\title{
Mamá Antula: la beata de los ejercicios espirituales desde la mirada de los jesuitas desterrados
}

\section{Mama Antula: the spiritual exercises devout woman from the perspective of the banished jesuits}

\author{
INMACULADA FERNÁNDEZ ARRILLAGA \\ arrillaga@ua.es
}

Universitat d'Alacant

\begin{abstract}
Resumen: Cuando en 1767 Carlos III expulsó a los jesuitas, una beata: $\mathrm{M}^{a}$ Antonia de San José, asumió la responsabilidad de continuar con la labor de estos religiosos, centrándose en la realización de los Ejercicios Espirituales al modo de San Ignacio por la Provincia de Paraguay. Analizamos aquí la influencia de estos jesuitas en su actividad misional y algunos de los comentarios que hicieron durante su exilio.
\end{abstract}

Palabras clave: jesuitas, beata, ejercicios espirituales, destierro

\begin{abstract}
When in 1767 Charles III of Spain expelled the Jesuits, a devout woman: Maria Antonia de San José, continued their work focusing on the realization of the Ignatian Spiritual Exercises along the Province of Paraguay. We analyze in this easy the influence of these religious on her missionary activity and the comments they wrote during their exile.
\end{abstract}

Keywords: Jesuits, devout woman, Ignatian spiritual exercises, exile 
Inmaculada Fernández Arrillaga. Mamá Antula: la beata de los ejercicios espirituales desde la mirada de los jesuitas desterrados

Cuando, en la primavera de 1767, Carlos III expulsó a los jesuitas de todos sus dominios (Ferrer 2013), ${ }^{1}$ hubo una serie de mujeres decididas a mantener vivo el ejemplo que habían dejado estos religiosos en su entorno, en sus conventos, en sus beaterios o incluso a extenderlo por otros lugares. Conocemos estas manifestaciones, fundamentalmente, gracias a los comentarios que estos mismos religiosos dejaron escritos en sus diarios, en su correspondencia o en anotaciones puntuales realizadas durante su largo destierro en los Estados Pontificios. Unas noticias que se fueron copiando de unos a otros y extendiendo para dar a conocer tan extraordinarios acontecimientos (Fernández 2013). El objetivo no era otro que justificar la inocencia de la Compañía de Jesús a través de las visiones o profecías de estas señoras, cuyo nexo común era el vínculo que habían tenido con ellos y la inquebrantable fe que todas ellas mostraban en la restauración de la Compañía de Jesús. De esta manera lograban varios objetivos: fomentar un modelo de mujer; demostrar al mundo la certera labor que como confesores de almas habían desarrollado antes de la expatriación, ejemplarizada en estas hijas espirituales; alentar sus propias esperanzas en un retorno no tan lejano a sus países de origen y seguir influyendo en las conciencias más refractarias a los cambios que proponían los nuevos tiempos modernos.

No era la primera vez que estos religiosos recopilaban datos sobre mujeres destacadas por su espiritualidad, Francisco Pons (2015a: 187-210) profundiza sobre la obra que el P. Cazorla escribió sobre la beata Gerónima Dolz y nos recuerda que ya en el XVII el P. la Puente (1665) realizó la biografía de Marina Escobar (Burrieza 2012), y en el XVIII Luis Ignacio Zevallos (1733) resaltó la Vida y virtudes de la capuchina $\mathrm{M}^{\mathrm{a}}$ Ángela Astorch mientras que a Mariana de San Simón la biografiaba otro jesuita, el P. Joseph Carrasco (1746), por resaltar alguno de los muchos que narraron vidas de mujeres de religiosidad ejemplar.

Algunas de estas mujeres, en tiempos de la expulsión de la Compañía en los territorios hispanos, van a saber esquivar las órdenes reales que prohibían la correspondencia con los expulsos y esas prácticas proféticas que ellas practicaban y les hacían llegar. ${ }^{2}$ Llegó un momento que las medidas se hicieron más rigurosas recibiendo serias advertencias desde la jerarquía eclesiástica. ${ }^{3}$ Pero ninguna resolución mermó la afluencia clandestina de misivas que llegaban a los jesuitas de sus feligresas, unas misivas que ellos ya registran en sus escritos desde el primer momento que iniciaron su viaje

1 Sobre bibliografía acerca de la expulsión, extinción y exilio véase la recopilada por Enrique Giménez López en: http://www.cervantesvirtual.com/portales/expulsion_jesuitas/bibliografia/

2 Biblioteca Nacional de Madrid (B.N.), MSS/19.173: Colección de papeles curiosos: Carta del José Moñino al obispo de Gerona, 80-99.

3 Fueron muchos los casos, por poner un ejemplo: Archivum Historicum Societatis Iesu Cataloniae, ACEX 25.04 «Carta pastoral València: A les religioses sobre revelacions fanàtiques (Arzobispo Andrés de Mayoral, en Valencia a 15de noviembre de 1767)» en Monjo i Dalmau, F-J. Expulsió, exili i retorn dels jesuïtes del País Valencià (1767-1816), tesis doctoral que obtuvo unánime Cum Laudem, el 11 de febrero de 2016, inédita, 148-149. 
Inmaculada Fernández Arrillaga. Mamá Antula: la beata de los ejercicios espirituales desde la mirada de los jesuitas desterrados

hacia el destierro ${ }^{4}$ y cuyo flujo no cesó hasta el retorno de la Compañía a la España de 1815 (Revuelta 2013). Otras van a extender visiones en las que se advertían castigos para los enemigos de la Compañía de Jesús; en ellas auguraban cambios favorables para los jesuitas y anunciaban el fin del destierro y de los sufrimientos que éste había impuesto a los religiosos (St. Clair 2003: 291-314). El caso más significativo y conocido fue el de la campesina de Valentano que predijo la fecha y hora de la muerte de Clemente XIV tras firmar el breve que extinguía la Compañía de Jesús (Caffiero 1991: 494-517). Y tenemos ejemplos puntuales de mujeres que no solo siguieron el ejemplo de los padres, incluso pretendieron sustituirlos, ocupando su lugar y favoreciendo e impulsando prácticas propias de la Compañía, como los Ejercicios Espirituales al modo de San Ignacio, justo el tema que trataremos más adelante (Gorostiaga 2008).

Por su parte ellas encontraron protección en los expulsos, reconocimiento, afecto y una proyección que, de no haber estado los jesuitas en el exilio, dudamos si hubieran tenido, dados los muchos prejuicios sociales que sobre estas visionarias existían (Caffiero 2000). El fomento de las actividades que desarrollaron estas mujeres espirituales hay que enmarcarlo pues en la difícil situación que aquellos religiosos estaban viviendo, sin olvidar que, en otras circunstancias, posiblemente no las hubieran favorecido. Nos cuesta imaginar a los jesuitas apoyándose en una beata para extender sus Ejercicios por la América virreinal, pudiendo hacerlo ellos mismos, o propagando castigos divinos profetizados por una campesina ignorante contra todo un pontífice por haber tomado medidas desfavorables hacia una Orden, de no haber sido la suya. Pero lo cierto es que a ellas también les favoreció este apoyo de hecho, supuso para algunas un reconocimiento social impensable en otras circunstancias e incluso favoreció, en determinados ambientes, su ascenso social y su proyección personal, marcando tendencias en actuaciones hasta entonces mal vistas en mujeres y convirtiéndose en el prototipo de una religiosidad femenina más activa, innovadora y valiente, como fue el caso de nuestra protagonista (Fraschina 2006: 758-771).

María Antonia de Paz y Figueroa, nació en 1730 en la norteña provincia argentina de Santiago del Estero, centro en aquel momento de la Intendencia de San Miguel de Tucumán, perteneciente al Virreinato del Río de la Plata y, en términos canónigos jesuitas, a la Provincia de Paraguay (Marcos 1947). Perla Montevideo por su parte, sitúa el probable lugar de nacimiento en Silípica «donde estaba la encomienda de indios de su padre, el Maestre de Campo Francisco Solano de Paz y Figueroa» (Montevideo 2014). Hay biógrafos de $\mathrm{M}^{a}$ Antonia de Paz, como Luis Antequera, ${ }^{5}$ que resaltan su ascendencia «ilustre de conquistadores y gobernadores» y sus «preciosas facciones con grandes ojos azules». ${ }^{6}$

\footnotetext{
4 Luengo, M. 2002. Diario de un exilio, Inmaculada Fernández Arrillaga (Ed.), Alicante, Publicaciones de la Universidad de Alicante.

5 Antequera, L.; La hispano argentina, http://www.mamaantula.org/ luis antequera/la hispano argentina.pdf/ (consulta de 23 de octubre de 2014)

6 Recordando a Mamá Antula, Casa de Ejercicios espirituales, Buenos Aires, 2013, en Mamá http://www.mamaantula. org/ (consulta de 8 de agosto de 2014)
} 
Inmaculada Fernández Arrillaga. Mamá Antula: la beata de los ejercicios espirituales desde la mirada de los jesuitas desterrados

A la edad de 15 años, decidió ofrecer su vida a Dios pero sin querer ingresar en ninguna Orden, ni contraer votos religiosos, es entonces cuando profesa como beata y se une al grupo de mujeres que formaba espiritualmente la Compañía de Jesús, convirtiéndose en lo que actualmente se denominaría una «laica consagrada». Entre sus tareas resaltaremos la ayuda que prestaba al P. Gaspar Juárez ${ }^{7}$ en la instrucción de menores y en el cuidado de personas necesitadas y enfermas. Este jesuita apadrinará a $\mathrm{M}^{\mathrm{a}}$ Antonia y la protegerá, al modo que hacían los confesores de beatas, acercando a estas mujeres hacia la orientación teológica de su orden y resguardándolas de las críticas que su labor pastoral pudiera originar. No olvidemos que esa religiosidad independiente, tan común entre las beatas, no siempre era valorada socialmente, de ahí que la mayoría de ellas quedaran sujetas al amparo de esos maestros de espíritu (Pons 2015b: 83-91)

En lo referente al P. Gaspar Juárez decir que era paisano de la beata y un año más joven que ella, había ingresado en la Compañía de Jesús en 1748 y estudió en el argentino Colegio de Córdoba donde llegó a ser Maestro de Teología y Sagrados Cánones. En ese mismo lugar residía cuando, la noche del 9 de agosto de 1767, le sorprendió la Pragmática Orden de expulsión que firmara Carlos III y por la que todos los religiosos pertenecientes a esta Orden tuvieron que abandonar los vastos territorios del monarca. La vida y obra de estos religiosos, los precedentes de esa expulsión (Burrieza 2007) y las consecuencias han sido profusamente estudiadas y seguirán siendo tema de debate (Andrés 2005), ya que bruscamente, con esta medida, en toda la América hispana y, más concretamente, en el Río de la Plata el mundo jesuítico se desplomó; en palabras de Alicia Franchina (2005: 707-730) para las misiones comenzó un periodo de desintegración, las estancias fueron vendidas, la universidad de Córdoba pasó a ser administrada por los frailes franciscanos, los colegios se clausuraron y las casas de Ejercicios se destinaron a fines más acordes con la nueva racionalidad. El P. Juárez, como todos sus compañeros, salió con rumbo a la metrópoli, desembarcando en El Puerto de Santa María en enero de 1768 y desde allí fue destinado a la entonces pontificia ciudad de Rávena, donde residió, durante los 49 años que duró el largo destierro, junto a sus hermanos de la Provincia de Paraguay. Sabemos que allí vivía en el verano de $1773,{ }^{8}$ cuando Clemente XIV firmó el Breve de extinción por el que quedaría suprimida la Compañía de Jesús hasta 1814 (Giménez 2008).

Desde el momento en que vio salir a los jesuitas de la Provincia de Paraguay, María Antonia de la Paz o Antonia del Señor San José, nombre que asume como religiosa, se propuso seguir con la labor que habían desarrollado sus queridos padres jesuitas, centrándose en un aspecto que quedó abandonado tras su partida: la práctica de los Ejercicios espirituales al modo de San Ignacio (Loyola: 1987). Comenzó, pues, reorganizando esta actividad en la ciudad donde habitaba, Santiago del Estero, pero sin olvidar las actividades docentes, caritativas y de asistencia a necesitados, que ya

\footnotetext{
7 Gaspar Juárez había nacido en Santiago del Estero (Tucumán) el 15 de julio de 1731. Pacheco Albalate, M. 2011. Jesuitas expulsos de ultramar arribados a El Puerto de Santa María (1767-1774), Universidad de Cádiz.

8 Archivo General de Simancas (a partir de aquí A.G.S.), Sección: Dirección General del Tesoro (DGT), Inventario 27, Legajo 1. El P. Juárez murió en Roma el 2 de enero de 1804. Agradecemos estos datos a Carlos Martínez Tornero.
} 
Inmaculada Fernández Arrillaga. Mamá Antula: la beata de los ejercicios espirituales desde la mirada de los jesuitas desterrados

llevaba adelante junto al P. Juárez. Con el fin de propagar los Ejercicios comienza una peregrinación por Jujuy, Salta y Tucumán, con la venia del obispo de esta última, un recorrido que la llevará hasta la ciudad de Buenos Aires (a unos 1.500 kms. de distancia) y de allí -cruzando el Río de la Plata- a Montevideo. En esa ciudad pasará tres años y retornará a la capital del Virreinato donde comenzó a impulsar a creación de una casa apropiada para la celebración de estos Ejercicios. Mamá Antula, como ya era conocida popularmente entre los indígenas, va a enfrentarse allí a las autoridades que intentaron frenar su impulso por el escándalo que, una práctica tan jesuita y el propio atuendo de la beata, tan similar al de los expulsos, hacían escandalizar a las autoridades. Pero allí se instaló, en un edificio, situado en el 1190 de la avenida de la Independencia, uno de los más antiguos de la ciudad y en el que todavía hoy se sigue realizando esta actividad.

Centrándonos ahora en la información que algunos de los desterrados tuvieron sobre las actividades de Mamá Antula, y más concretamente sobre lo que anotó el castellano Manuel Luengo, uno de los diaristas más prolijos del destierro que sufrieron los jesuitas en los Estados Pontificios, ${ }^{9}$ diremos que la primera referencia completa que encontramos sobre ella en su Diario aparece el año 1785, y aunque ya había dado algunas pistas sobre los rumores que le llegaban de la acción que estaba desarrollando $\mathrm{M}^{\mathrm{a}}$ Antonia de San José, en esta ocasión el diarista nos ofrece un relato amplio y apologético de esa «mujer singular, grande y extraordinaria que en las provincias de Tucumán, Paraguay y Buenos Aires, se emplea con el mayor suceso en promover el uso de los Ejercicios Espirituales de San Ignacio». ${ }^{10}$

A partir de aquí se centra en la correspondencia que tenía $\mathrm{M}^{\mathrm{a}}$ Antonia de San José con el que fuera su confesor antes de la expulsión y que, según algunos rumores, podría ser tío suyo, si bien Manuel Luengo en ningún momento da el nombre del P. Juárez. Aseguraba el diarista que había sido un religioso de gran prudencia al haber sabido velar algunas de las proezas realizadas por esta beata ya que, publicadas sin las necesarias precauciones, hubieran podido perjudicar a ella e incluso a los propios expulsos.

Respecto a los comentarios de la biografía que le había llegado a Luengo, repite los datos que ya conocemos con muy sutiles variaciones; vemos cómo describe la buena familia de la que procedía esta beata en Santiago del Estero y cómo a los 30 años, cuando fueron desterrados los jesuitas, vivía retirada en un beaterio con otras compañeras «vestidas todas de la ropa de la Compañía». Nada hacía sospechar el coraje del que después va a hacer gala, porque hasta ese momento «su genio tímido y pusilánime la hacían poco proporcionada para una empresa» como la que emprendería. Pero la aflicción que le había causado la expulsión de estos religiosos había promovido en ella el empeño de llevar a nuevos territorios la práctica de los Ejercicios. Describe después el viaje a pie «y aun descalza» desde su ciudad natal, acompañada por otra compañera y con dos criadas, en el

9 Luengo, M. Diario de la expulsión de los jesuitas de España, (A partir de aquí Diario), Archivo Histórico de Loyola (A.H.L.), Sección jesuitas del XVIII, Azpeitia.

10 Luengo, M. Diario, T. XVIII, 7 de abril de 1784.

SCRIPTA, Revista internacional de literatura i cultura medieval i moderna, núm. 8 / desembre 2016 / pp. 257-267 ISSN: 2340-4841 · doi:10.7203/SCRIPTA.8.9298 
Inmaculada Fernández Arrillaga. Mamá Antula: la beata de los ejercicios espirituales desde la mirada de los jesuitas desterrados

que recorrieron ciudades, cruz en mano, para conseguir su objetivo. Resalta los muchos problemas que fue encontrando, las resistencias y cómo todo lo «ha vencido con su paciencia, mansedumbre, humildad, constancia y con su fervorosa oración». Desde la perspectiva de un jesuita, virtudes todas ellas muy apropiadas en una mujer espiritual de la época. Logrando que se dieran Ejercicios en Jujuy, Salta, San Miguel de Tucumán, San Fernando, Rioja, Córdoba y Buenos Aires.

Continúa el diarista comentando las dificultades que tuvo Antonia de San José en la ciudad bonaerense, refiriendo los propios comentarios que realizaba ella en carta a su confesor de 7 de agosto de $1780,{ }^{11}$ en la que aseguraba que no habían obtenido licencia del obispo en el año que llevaban allí para realizar los ejercicios y explicaba después como la obtención de ese permiso le llevo unos dos años. En el juicio inicial del jesuita la causa estaba clara: se trataba de un obispo favorable a los ministros de Carlos III y totalmente influenciado por el confesor real. Pero después, cuando Luengo tiene acceso al informe de este prelado, muda su opinión y transcribe el memorial de la propia Antonia de San José al Obispo, como el informe de este prelado de Buenos Aires a Pío VI. ${ }^{12}$

En el primero, la beata jesuita solicita diversos privilegios para poder llevar a cabo la realización de los Ejercicios aunque lo más significativo queda reflejado en el segundo documento, en él Fray Sebastián Malvar y Pinto informa al Papa de las actividades de la beata. Por entonces, Mamá Antula ya llevaba doce años dando los Ejercicios en Tucumán, en opinión del obispo «con imponderable fruto de las almas».

\begin{abstract}
Llegó a ésta, nuestra diócesis de Buenos Aires, a fines del año 1772. Solicitó nuestra licencia para abrir una casa pública de ejercicios espirituales, no consideramos por entonces oportuno el conceder con sus ruegos hasta tantear y enterarnos bien de la idea y fondo de esta misión. Por espacio de nueve meses continuos examinamos por nos mismo el espíritu y fines de este pensamiento, desengañándola desde el principio [...] No se turbó ni se desalentó su espíritu con esta respuesta ni [...] nos fue molesta con sus ruegos o haciendo que otras personas nos hablasen. Se nos presentaba de tiempo en tiempo, oía con humildad la respuesta y partía de nuestra presencia con alegría y confianza. [...] y finalmente porque aquel Señor que elige lo enfermo y débil para confundir lo robusto y fuerte nos movió el ánimo, le concedimos lo que deseaba. ${ }^{13}$
\end{abstract}

Continuaba describiendo el obispo Malvar cómo se abrieron los Ejercicios en aquella ciudad en 1780, los éxitos obtenidos por Mamá Antula, que en cuatro años pasaban de quince mil las personas que los habían realizado «sin que se les haya pedido dinero alguno por los diez días de su estancia y abundante manutención», subrayando que aunque se había ofrecido él mismo para ayudar económicamente, eran muy excepcionales las veces que había acudido a solicitar algo.

11 Luengo, M. Colección de Papeles Varios, (a partir de aquí Colección), A.H.L., Sección manuscritos jesuitas del XVIII, Tomo 14, 133-135

12 Luengo, M. Colección, T. 15, 147-149.

13 Ibidem, 147-148

SCRIPTA, Revista internacional de literatura i cultura medieval i moderna, núm. 8 / desembre 2016 / pp. 257-267 ISSN: 2340-4841 · doi:10.7203/SCRIPTA.8.9298 
Inmaculada Fernández Arrillaga. Mamá Antula: la beata de los ejercicios espirituales desde la mirada de los jesuitas desterrados

Por lo que se refiere al modo que utilizaba $\mathrm{M}^{a}$ Antonia de San José para desarrollar su labor, también el P. Luengo aseguraba que, después de conseguir la licencia de los superiores, la beata y sus compañeras se encargaban de todo: buscaban casa, la proveían de lo necesario para que pudieran vivir en ella de 50 a 200 personas, encontraban el modo de alimentar a todos los participantes y organizaban los calendarios con las semanas en las que realizarían los Ejercicios varones y las que lo harían mujeres. Lo que parecía más difícil: encontrar a sacerdotes que sustituyeran a los jesuitas, lo consiguieron ellas sin obstáculos y entre estos clérigos el P. Luengo resalta la fervorosa labor del mercedario descalzo Fray Diego Toro.

Tal fue la confianza del obispo bonaerense en el modo en que se ofrecían esos Ejercicios que antes de embarcar hacia la metrópoli, para tomar posesión como Arzobispo de Santiago, él mismo los hizo y « viendo pues, ya no por narrativas ni observaciones especulativas, sino por lo que nos mismo hemos visto y experimentado, aseguramos a Vuestra Santidad ser del mayor provecho y utilidad que pueda imaginarse» ${ }^{14}$ De ahí que le hubiera otorgado a $\mathrm{M}^{\mathrm{a}}$ Antonia de San José tantas gracias, indulgencias y privilegios «así como por lo que por derecho nos toca como por razón de las particulares facultades que nos tiene concedidas la Silla Apostólica». Terminaba su informe recomendándole al Papa que no dudara en conceder a Mamá Antula cuantas gracias y privilegios hallase conveniente.

Alicia Fraschina (2005:705) en lo referente a la correspondencia que la beata mantuvo con el jesuita desterrado, resalta que en sus cartas Mamá Antula dejó siempre claro que no era empeño propio esa misión sino que «Jesucristo es quien dirige mis pasos para recoger la mies que a vuestras mercedes no les ha sido permitido adquirir por su profesión». Una afirmación en la que se percibe cómo se sentía destinada por Dios a seguir los pasos de la Compañía de Jesús, algo muy propio de aquellas mujeres espirituales, lo que va a sorprender en el caso de Antonia de San José no es tanto ese auto convencimiento de que su trabajo a favor de los Ejercicios era una predestinación y que poco podía hacer ella para evitarlo, sino que se siente, habla y describe su misión igualándola a la que ejercían los jesuitas, algo que cala también en los desterrados ya que el jesuita italiano que traduce algunas de sus cartas llega a asegurar que la labor de esta beata es mayor de la que pudieran haber hecho los propios jesuitas de haber seguido en aquellas tierras ${ }^{15}$. También da la impresión de que se comportaban como si fueran auténticas terciarias cuando describe la labor e impulso que llevó a sus hermanas a vestir «el hábito de la Compañía», así le escribe a su confesor:

Estas son conocidas de usted pues ya cuando estaban en el Colegio de Santiago ya vestían la sotana jesuita a forma de religiosas y vivían en retiro. Con aquel amor de hermanas en Jesucristo y como hijas que habíamos sido de una misma madre: la Compañía de Jesús en la doctrina y educación espiritual, unidas para promover los Ejercicios y para servir por amor de Dios a las personas que los hacían... ${ }^{16}$

14 Ibidem, 149.

15 «Nuestra beata está haciendo en esta ciudad más que cuanto hacían los nuestros en toda la Provincia», Luengo, M. Diario, T. XVIII, 7 de abril de 1784.

16 Luengo. M. Colección, T. 15, 218. Carta de 26 de mayo de 1785.

SCRIPTA, Revista internacional de literatura i cultura medieval i moderna, núm. 8 / desembre 2016 / pp. 257-267 ISSN: 2340-4841 · doi:10.7203/SCRIPTA.8.9298 
Inmaculada Fernández Arrillaga. Mamá Antula: la beata de los ejercicios espirituales desde la mirada de los jesuitas desterrados

Retomemos aquí la idea anterior de actitudes en mujeres del XVIII absolutamente impensables si no hubieran sido expulsados los jesuitas. Un aspecto que queda recogido en otras ocasiones, como observamos en esas copias de las cartas que Manuel Luengo conservó después de calcarlas en su Colección de Papeles Varios. Tres de ellas, escritas por la beata a su confesor, aparecen escritas en italiano gracias a un jesuita de esa nacionalidad que las había traducido, pero del que tampoco da su nombre.

La primera, fechada el 6 de enero de 1778, la segunda del 7 de agosto de 1780 y la última de 9 de octubre de $1782 .{ }^{17}$ Además, poco tiempo después, Luengo tuvo acceso a otras dos, transcribiéndolas esta vez en castellano, fechadas ambas en 1785, una el 29 de marzo y la otra el 26 de mayo. Y en todas ellas nos sorprende este aspecto al que nos estamos refiriendo, el trato de igual a igual que utiliza la beata, llamando hermano a su confesor y dando a entender que lo son ambos por seguir la misma estela espiritual, la que marcara $\operatorname{San} \operatorname{Ignacio}^{18} \mathrm{y}$, aunque de su lenguaje podría deducirse sumisión, lo cierto es que si bien se observa aprecio hacia los consejos que le da el P. Juárez, se percibe de sus comentarios que es ella quien toma sus propias decisiones, actuando confiada y desde el ejemplo que siempre ha tenido de ese espíritu jesuita, tan llamado a viajar sin desmayo hasta el último rincón para llevar a buen término su misión:

\begin{abstract}
Las otras cosas que usted me pregunta no puedo decírselas con claridad porque ni yo tampoco las sé, ni llego a comprenderlas. No se pues decir a usted cómo ha sido que Dios Nuestro Señor me hiciese comprender la promoción de los Ejercicios, ni como me ha hecho llevarla adelante hasta el presente. Solo se decir a usted que me hallo ya avanzada de edad, nunca he sido buena y cada día soy peor. Cada noche me parece debe ser la última de mi vida y, con todo eso, cada nueva mañana me hallo con un espíritu tan grande y tan valiente que quisiera ir hasta los últimos fines de la tierra donde Dios no es conocido para hacer que sea amado de todas las criaturas. ${ }^{19}$
\end{abstract}

Toda esta correspondencia de Mamá Antula ha sido estudiada desde muy diversas perspectivas, recogida en Diarios, como el referido del P. Luengo y estudiada por investigadores como el también jesuita Guillermo Furlong (1929: 232-242), quien publicó doce cartas que envió la beata a Ambrosio Funes. Posteriormente, Alicia Fraschina estudió las veintitrés misivas que envió Ma Antonia de Paz al P. Gaspar Juárez, resaltando que fue este expulso quien extendió entre sus hermanos primero, y a nivel internacional después, estas cartas de Mamá Antula, llegando a encargar la traducción de las mismas a diferentes lenguas. ${ }^{20}$ De hecho, en 1791 se publicaron bajo el título «El estandarte de la mujer fuerte» (San Jose 1899).

17 Luengo, M. Colección, T. 14, 131-135.

18 «De otras cartas mías habrá usted inferido que los ejercicios que hago se tengan, en nada son diferentes de los que daban ustedes» y más adelante: «los medios espirituales que yo he usado han sido siempre los mismos que usaban ustedes» en Luengo. M. Colección, T. 15, 218. Carta de 26 de mayo de 1785.

19 Ibidem, T. 15, 221.

20 Estas cartas se custodian en el Archivio di Stato di Roma (ASR), Amministrazione Camerale del Patrimonio exgesuitico. Buste 718. Corrispondenza riguardante l'esecuzione del breve di soppressione (1773-1775). 
Inmaculada Fernández Arrillaga. Mamá Antula: la beata de los ejercicios espirituales desde la mirada de los jesuitas desterrados

Así pues, creemos que hay elementos suficientes para afirmar que estas beatas incondicionales significaron un referente y un excepcional apoyo para la moral de los exiliados alejados de sus lugares de origen o de aquellos en los que habían realizado su labor pastoral. Son mujeres importantísimas para levantar su ánimo, para consolar su atormentado espíritu y se apoyarán en sus alentadoras predicciones y en sus virtuosas prácticas femeninas para así demostrar al mundo la injusticia de su expatriación (Fernández 1998: 83-98). Si bien ellos fueron quienes las aconsejaron, las que velaron porque sus memorias no pasaran inadvertidas realizando gran parte de sus biografías, como vimos al inicio, también obtuvieron el fruto de esos esfuerzos al verse compensados por la fidelidad que ellas les profesaron en los momentos difíciles, con una actitud decidida, firme y valiente, algo que ellos supieron valorar y publicitar. De hecho y como ya hemos advertido, son los expulsos quienes dejan noticia de las actividades de estas profetisas o religiosas, conservando sus cartas, realizando copias de las mismas y extendiéndolas entre los jesuitas instalados en otras legacías e incluso enviándolas a otros países (Fernández 2000: 211-227). En ocasiones, convertirán la vida de estas mujeres en modelos de virtud católica, de la religiosidad que ellos defendían y que Luengo enmarcaba en virtudes como: paciencia, mansedumbre, humildad... Todas ellas parecían formar parte de la personalidad de $\mathrm{M}^{\mathrm{a}}$ Antonia de San José, una mujer extraordinaria para los expulsos, pero no solo por ser la «verdadera heroína, la apóstol de los Ejercicios de San Ignacio» sino también por profetizar en 1786 la próxima restitución de la Compañía de Jesús». ${ }^{21}$

Mamá Antula falleció el 7 de marzo de 1799 en la Casa de Ejercicios que fundó en Buenos Aires, contaba entonces 69 años. Sus restos se encuentran en la Basílica de Nuestra Señora de la Piedad, en la misma ciudad. Su causa de beatificación fue la primera en la historia de Argentina, se inició en 1905 y se elevó a Roma el 8 de agosto de 1917, firmando Benedicto XV el Decreto de introducción. Ya en 2010, Benedicto XVI, promulgó el Decreto por el que $\mathrm{M}^{a}$ Antonia de Paz se convertía en «Venerable» (Saenz Quesada 1941). ${ }^{22}$

21 Luengo, M. Diario, T. XX, conclusiones anuales al terminar 1787.

22 En la actualidad podemos obtener información sobre $\mathrm{M}^{\mathrm{a}}$ Antonia de San José en su página web donde puede visualizarse una película sobre su vida y un video para la difusión del apoyo a la beatificación de Mamá Antula. En Facebook: https://www.facebook.com/ProBeatificacionyCanonizacionDeMamaAntula. Y en otras aplicaciones TIC que se mantienen al día con información sobre ella y sus devociones http://es.wikipedia.org/wiki/Mar\% $\% 3 \% A D a$ Antonia_de_Paz_y_Figueroa 
Inmaculada Fernández Arrillaga. Mamá Antula: la beata de los ejercicios espirituales desde la mirada de

los jesuitas desterrados

\section{Bibliografia}

Andrés Gallego, J. (dir.) (2005) Tres grandes cuestiones de la Historia de Iberoamérica, Impacto en América de la expulsión de los jesuitas, Madrid, Mapfre/ Fundación Ignacio Larramendi.

Burrieza Sánchez, J. (2002) Los milagros de la Corte. Marina de Escobary Luisa de Carvajal en la historia de Valladolid, Valladolid, Junta de Castilla y León.

- (2007) Jesuitas en indias: entre la utopía y el conflicto. Trabajos y misiones de la Compañia de Jesús en la América Moderna, Valladolid, Universidad de Valladolid.

Caffiero, M. (1991) «Le profetesse di Valentano». Finzione e santità tra medioevo ed età moderna, Roma, Gabriella Zarri 494- 517.

—. (2000) Religione e modernità in Italia (secoli XVII- XIX), Pisa-Roma, Istituti Editoriali Poligrafici Internazionali.

Carrasco, J. (1746) La Phenix de Murcia. Vida, virtudes y prodigios de la Venerable madre Mariana de San Simeón, Madrid.

Fernández Arrillaga, I. (1998) «Profecías, coplas, creencias y devociones de los jesuitas expulsos durante su exilio en Italia», Revista de Historia Moderna, 16, pp. 83-98.

- (2000) «Manuscritos sobre la expulsión y el exilio de los jesuitas (1767-1815)», Hispania Sacra, 52, pp. 211-227.

Fernández Arrillaga, I (2013) Tiempo que pasa, verdad que buye. Crónicas inéditas de jesuitas expulsados por Carlos III (1767-1815), Alicante, Publicaciones Universidad de Alicante.

Ferrer Benimeli, J. A. (2013) Expulsión y extinción de los jesuitas (1759-1773), Bilbao, Mensajero.

Fraschina, A. (2005) «La cuestión autobiográfica en el epistolario de María Antonia de San José, Beata de la Compañía de Jesús, 1730-1799» en Viforcos Marinas, M. I. y Cantos M.D. (coords.) Fundadores, fundaciones y espacios de vida conventual. Nuevas aportaciones al monacato femenino, León, Universidad de León, pp.705-730

- (2006) «A jesuit Beata at the time of the Suppression in the Viceroyalty of Rio de la Plata: María Antonia de Paz y Figueroa (1730-1799)», 758-771 en O’Malley, J. W. 1006. The Jesuits, II, Culture, Sciencies and the Arts (1540-1773), University of Toronto.

Furlong, G. (1929) «Cartas inéditas de María Antonia de San José», Estudios, Academia Literaria de La Plata, pp. 232-242.

Giménez López, E. (2008) Misión en Roma: Floridablanca y la extinción de los jesuitas, Murcia, Universidad de Murcia.

Gorostiaga Saldías, L. (2008). María Antonia de Pazy Figueroa. La beata de los ejercicios (1730-1799), Buenos Aires, Dunken.

La Puente, L. de (1665) Vida maravillosa de la venerable virgen doña Marina Escobar, natural de Valladolid, 
Inmaculada Fernández Arrillaga. Mamá Antula: la beata de los ejercicios espirituales desde la mirada de los jesuitas desterrados

sacada de lo que ella misma escribió de orden de sus padres espirituales, Madrid.

Loyola, I. de (1987, original) Ejercicios espirituales, Cándido de Dalmases (ed.), Bilbao, Sal Terrae.

Marcos Ezcurra, M. (1947) Vida de Sor María Antonia de la Paæz, Buenos Aires, Sebastián de Amorrortu e hijos.

Montevideo de Mollo, P (2014) «Sor María Antonia de Paz y Figueroa: de su orientación originaria» en: www.enduc.org.ar/comistin/ponencia/401-405.

Pons Fuster, Francisco (2015a) «Un jesuita y una beata. La milagrosa relación del jesuita Blas Antonio Cazorla y la beata Gerónima Dolz», La catedral ilustrada. Iglesia, sociedady cultura en la Valencia del siglo XVIII, (Vol. 3), Emilio Callado Estela Ed. Valencia, Institut Alfons el Magnanim. 187-210.

—_. (2015b) «La religiosidad femenina en el antiguo reino de Valencia» en Fernández Arrillaga, I. (coord.) Mujeres que vivieron el Alicante de la Modernidad, Alicante, Instituto Alicantino de Cultura «Juan Gil-Albert», pp. 83-91.

Revuelta González, M. (2013) El restablecimiento de la Compañia de Jesús. Celebración del bicentenario, Bilbao, Mensajero.

Saenz Quesada de Saenz, L. (1941) María Antonia de Pazy Figueroa, Buenos Aires, CEPA.

San José, M ${ }^{a}$ A. de (1899) El estandarte de la mujer fuerte en nuestros días, Buenos Aires, Biedina e Hijo Ed.

St. Clair Segurado, E. Ma . (2003) «Padrecito, los padres jesuitas vuelven. Revelaciones, profecías y otros hechos maravillosos en Nueva España tras la expulsión de la Compañía de Jesús (17671772)», Revista de Historia Moderna. Anales de la Universidad de Alicante, 21, pp. 291-314.

Zeballos, L. I. (1733) Vida y virtudes, favores del cielo, milagros y prodigios de la V. madre sor Ángela de Astorch, religiosa capuchina, Madrid. 